\title{
Radiographic Assessment of Effect of Congenital Monosegment Synostosis of Lower Cervical Spine between C2-C6 on Adjacent Mobile Segments
}

\author{
Myung-Sang Moon ${ }^{1}$, Sung-Soo Kim ${ }^{1}$, Min-Geun Yoon ${ }^{1}$, Young Hoon Seo ${ }^{1}$, \\ Bong-Jin Lee ${ }^{2}$, Hanlim Moon ${ }^{3}$, Sung-Sim Kim ${ }^{4}$ \\ ${ }^{I}$ Department of Orthopedic Surgery and Traumatology, Cheju Halla General Hospital, Jeju, Korea \\ ${ }^{2}$ Department of Orthopedic Surgery, Dong-In Medical Center, Gangneung, Korea \\ ${ }^{3}$ CUREnCARE Research, Seoul, Korea \\ ${ }^{4}$ Moon-Kim's Institute of Orthopedic Research, Seoul, Korea
}

\begin{abstract}
Study Design: A prospective radiographic study of cervical spine with congenital monosegment fusion.
Purpose: To evaluate the effect of cervical synostosis on adjacent segments and the vertebral morphology.

Overview of Literature: There are numerous clinical studies of adjacent segment disease (ASD) after monosegment surgical fusion. However, there was no report on ASD in the cervical spine with congenital monosegment synostosis.

Methods: Radiograms of 52 patients, aged 5 to 90 years, with congenital monosegment synostosis (CMS) between C2 and C6, who complained of neck/shoulder discomfort or pain were studied. 51 were normally aligned and one was kyphotically aligned.

Results: Spondylosis was not found in the patients below 35 years of age. Only 12 out of 24 patients with normally aligned C2-3 synostosis had spondylosis in 19 more caudal segments, and only one at C3-4. A patient with kyphotic C2-3 had spondylolysis at C3-4. In 8 patients with C3-4 synostosis, spondylosis was found in only 9 caudal segments (4 at C4-5, 4 at C5-6, and 1 at C6-7). The caudate $\mathrm{C} 4-5$ disc was the most liable to degenerate in comparison with other caudate segments. Caudal corporal flaring and inwaisting of the synostotic vertebra were the features that were the most evident. In 2 of 9 C4-5 and 7 out of 10 C5-6 synostosis patients, spondylosis was found at the two adjacent cephalad and caudate segments, respectively. Only corporal inwaisting without flaring was found. In all cases, spondylosis was confined to the adjacent segments. More advanced spondylosis was found in the immediate caudal segment than the cephalad one.

Conclusions: It is concluded that spondylosis at the mobile segments in a synostotic spine is thought to be a fusion-related pathology rather than solely age-related disc degeneration. Those data suggested that CMS definitely precipitated the disc degeneration in the adjacent segments.
\end{abstract}

Keywords: Synostosis; Cervical; Congenital; Alignment; Adjacent segment disease

\section{Introduction}

Congenital cervical monosegment synostosis is a type of failed segmentation of unknown origin. It has two morphological alignment types: normally and abnormally aligned ones. Some consider it an incidental radiological

Received Sep 25, 2013; Revised Oct 3, 2013; Accepted Oct 3, 2013

Corresponding author: Sung-Soo Kim

Department of Orthopedic Surgery and Traumatology, Cheju Halla General Hospital,

65 Doryeong-ro, Jeju 690-766, Korea

Tel: +82-64-740-5030, Fax: +82-64-740-5671(Orthopedics), E-mail: msmoonos@hotmail.com 
Table 1. Monosegment synostosis of 4 different levels between C2-C6 on incidences of adjacent segment spondylosis (disc degeneration)

\begin{tabular}{|c|c|c|c|c|c|c|c|c|}
\hline \multirow{2}{*}{$\begin{array}{l}\text { Level of } \\
\text { synostosis }\end{array}$} & \multirow{2}{*}{$\begin{array}{l}\text { No. of materials and } \\
\text { ages (male/female) }\end{array}$} & \multicolumn{7}{|c|}{ Level of disc degeneration } \\
\hline & & C1-2 & $\mathrm{C} 2-3$ & C3-4 & $\mathrm{C} 4-5$ & $\mathrm{C} 5-6$ & $\mathrm{C6}-7$ & C7-T1 \\
\hline C2-3 & $\begin{array}{c}25(11 / 14) \\
5-74 \mathrm{yr}\end{array}$ & $1^{\text {d) }}$ & - & $1^{c)}$ & $7^{\text {c) }}$ & $9^{c)}$ & $3^{c)}$ & 0 \\
\hline C3-4 & $\begin{array}{c}8(6 / 2) \\
13-69 \mathrm{yr}\end{array}$ & 0 & 0 & - & $4^{\mathrm{a}-\mathrm{dl}}$ & $4^{a-d)}$ & $1^{\text {b) }}$ & 0 \\
\hline C4-5 & $\begin{array}{c}9(6 / 3) \\
20-90 \mathrm{yr}\end{array}$ & - & $1^{\text {b) }}$ & $2^{a-d)}$ & - & $2^{a, b)}$ & $1^{c)}$ & 0 \\
\hline C5-6 & $\begin{array}{l}10(5 / 5) \\
11-67 \mathrm{yr}\end{array}$ & - & - & $1^{b)}$ & $2^{b, c)}$ & - & $3^{\mathrm{b}-\mathrm{dl}}$ & $1^{\text {a) }}$ \\
\hline Total & $\begin{array}{c}52(28 / 24) \\
5-90 \mathrm{yr}\end{array}$ & 1 & 1 & 4 & 13 & 15 & 8 & 1 \\
\hline
\end{tabular}

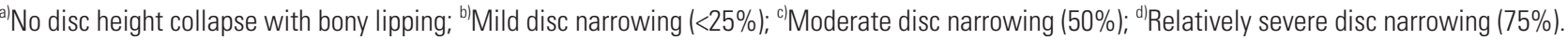

finding unrelated to disease, while others consider it to be the cause of secondary mobility disturbances and degenerative changes of the adjacent segments in the same manner that an iatrogenically created immobile segment does [1-9]. Generally, it has been known that an iatrogenically created immobile segment in the spine predisposes to alterations of the biomechanics at the neighboring mobile segments and may result in high demands on the adjacent intervertebral segments; in addition, instability and degenerative changes at the adjacent segments (ASD) may occur, although completely opposite opinions have also been reported. Of course, it is already known that the incidence of ASD is higher in the cases of surgical lumbar spine fusion than cervical spine fusion, and that the incidence of ASD in thoracic spine fusion is the lowest [10-15].
We evaluated the morphologies of the synostotic cervical vertebra of different levels on radiograms and their effect on the cephalad and caudal adjacent discs and vertebrae.

\section{Material and Methods}

Radiographs of 52 patients ( 28 males and 24 females), aged 5 to 90 years, with congenital monosegment synostosis between C2 and C6, obtained at 7 hospitals between April 1995 to May 2012, were reviewed. All cases were found incidentally on radiograms (Table 1).

No patient clinically presented with an obvious shortneck appearance. The patients' complaints included neck/ shoulder discomfort/pain $(n=23)$, neck motion limitation $(\mathrm{n}=6)$, an acute wry neck, which was possibly an atlanto-
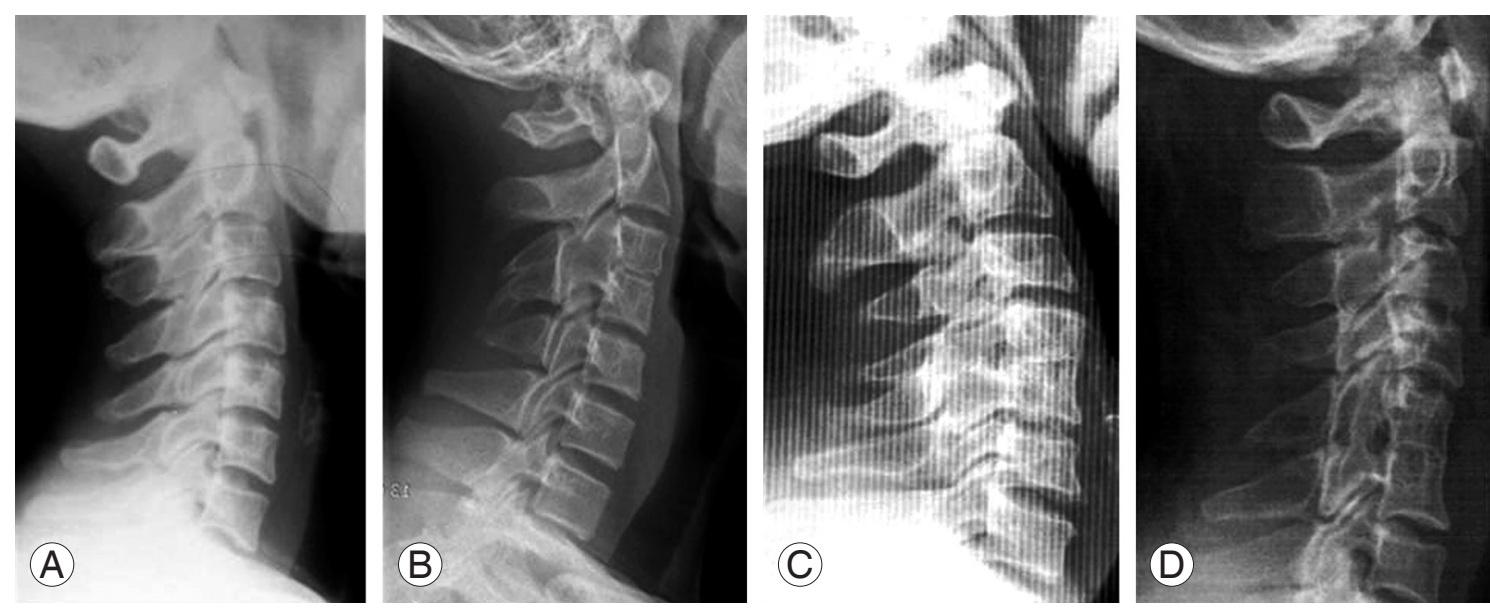

Fig. 1. Congenital monosegment synostosis with intact adjacent joints at 4 different levels are shown: (A) C2-3 synostosis, (B) C3-4 synostosis, (C) C4-5 synostosis, (D) C5-6 synostosis. 
axial rotatory subluxation (a 5-year-old boy), and posttraumatic transient myelopathy symptoms (SCIWORA; a 44-year-old man).

There was synostosis at four different levels: $\mathrm{C} 2-3$ in 25 ( 11 male/14 females), C3-4 in 8 (6 males/2 females), C4-5 in 9 (6 males/ 3 females), and C5-6 in 10 patients (5 males/5 females) (Fig. 1).

The patients' ages ranged from 5 to 90 years: 5 to 74 years in C2-3 synostosis cases, 13 to 69 years in C3-4, 22 to 90 years in C4-5, and 11 to 67 years in C5-6 synostosis.

Neutral anteroposterior and lateral radiograms were obtained to evaluate the effect of the synostosis and its alignment on adjacent segments and vertebral bodies, the segmental mobility, cervical curve, and to assess the morphology of the synostotic vertebra and discs.

\section{Results}

The most common patients' complaints were nuchal discomfort/pain ( $\mathrm{n}=23$ patients). The other combined conditions were wry neck in a child (Fig. 2), neck motion limitation in 6 adults, herniated disc symptoms at C3-4 in an adult, SCIWORA in an adult, and C1 ring hypoplasia in an adult. In none was a short neck appearance found even in the case of kyphotic C2-3 synostosis (Fig. 3). All patients had a normal canal size of the lower cervical spine with the Pavlov ratio over 0.8 .

1) Spondylosis were found in 13 out of 25 patients
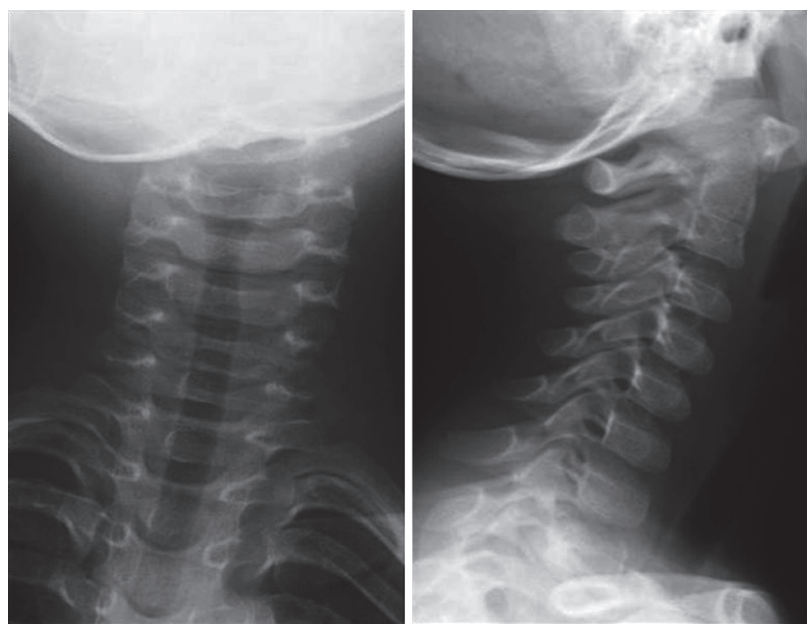

Fig. 2. Acute onset torticollis in a 5-year-old boy without cervical disc degeneration, segmental instability, and other anomaly. The torticollis was thought to be unrelated with the C2-3 block vertebra, and to be caused by the sudden development of atlantoaxial rotatory subluxation after a bout of illness with the flu. with C2-3 synostosis over the age of 40 years. Most of the cases of spondylosis were distributed in C4-5 and C5-6, and immediate adjacent segment involvement was found in only 2 patients (C1-2 in one [Fig. 4] and C3-4 in one, each). Among the twelve patients with normally aligned C2-3 synostosis, 8 had single level disc degeneration, 4 had 2 levels, and 1 had three levels (Fig. 5). C3-4 disc degeneration and $\mathrm{C} 4$ retrolisthesis in the compensatory hyperlodortic curve were found in a patient with kyphotic
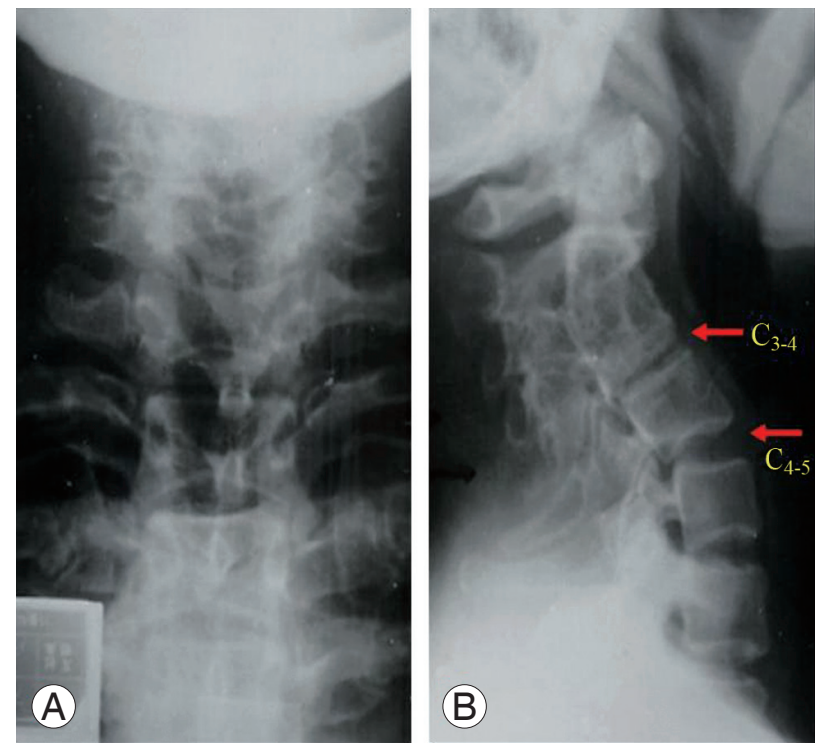

Fig. 3. Kyphotic C2-3 block vertebrae in a 43-year-old female (A, B): Compensatory hyperlordosis of the caudal mobile segments, spondylosis at C3-4, and C4 retrolisthesis were complications. She had no neurological compromise.
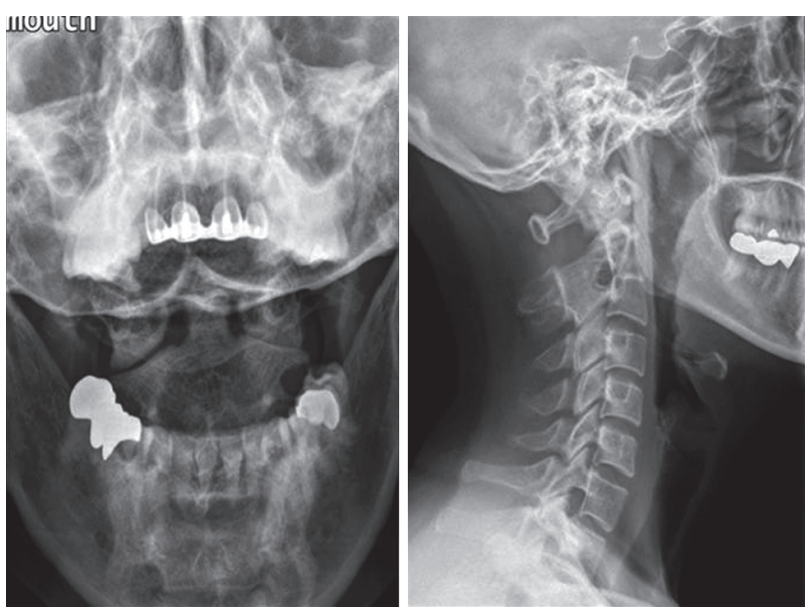

Fig. 4. A 40-year-old lady with a C2-3 synostosis sustained injury of the neck. Left atlantoaxial facet (C1-2) arthrosis was found incidentally on plain radiograms. She was asymptomatic before the injury. No degenerative disc disease was found at the caudal mobile segments. 
synostosis.

2) In 8 cases of C3-4 synostosis, the incidence of spondylosis was $62.5 \%$; there was no spondylosis in the cephalad motion segments, while spondylosis was localized only to the caudal segments: C4-5 (4 patients), C5-6 segments (4 patients) and C5-6 segments (1 patient) (Fig. 6). Caudal corporal flaring and inwaisting of the synostotic vertebra were most evidently shown. Adaptive morphological enlargement of the caudal part of the synostotic vertebra and disc could not lessen the severity and progress of adjacent segment disease of the caudate segments.

3) Among 9 patients with C4-5 synostosis, two (25\%) out of 9 patients had spondylosis at the cephalad C3-4 segment, while 2 had spondylosis at caudate C5-6 (2)
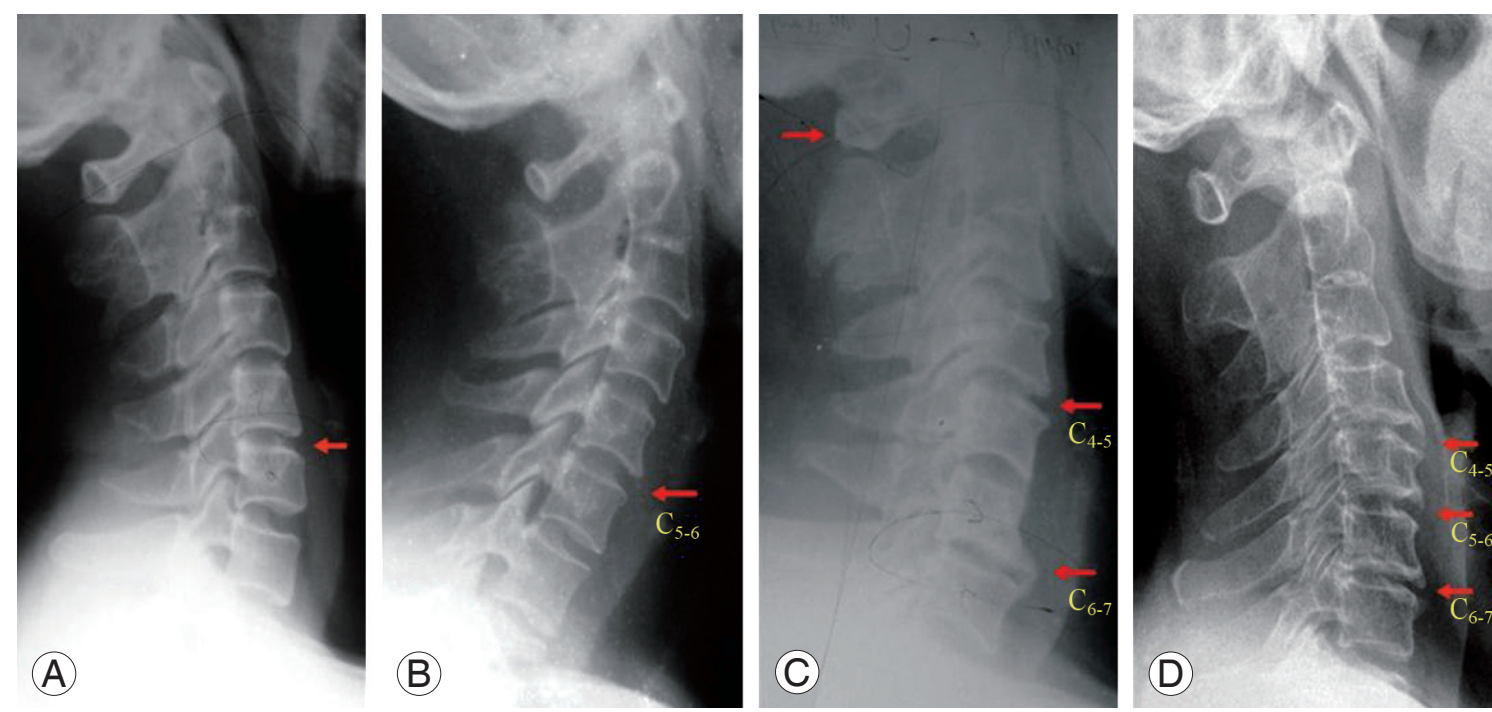

Fig. 5. Lateral radiograms of the cervical spines of 4 subjects with C2-3 synostosis showing spondylotic segments. (A, B) Monosegment spondylosis at C5-6 in a 51-year-old and a 54-year-old female. (C) Two-segment spondylosis at C4-5 and C6-7 in a 55-year-old male. (D) Three-segment spondylosis at C4-5, C5-6, and C6-7 in a 52-year-old male
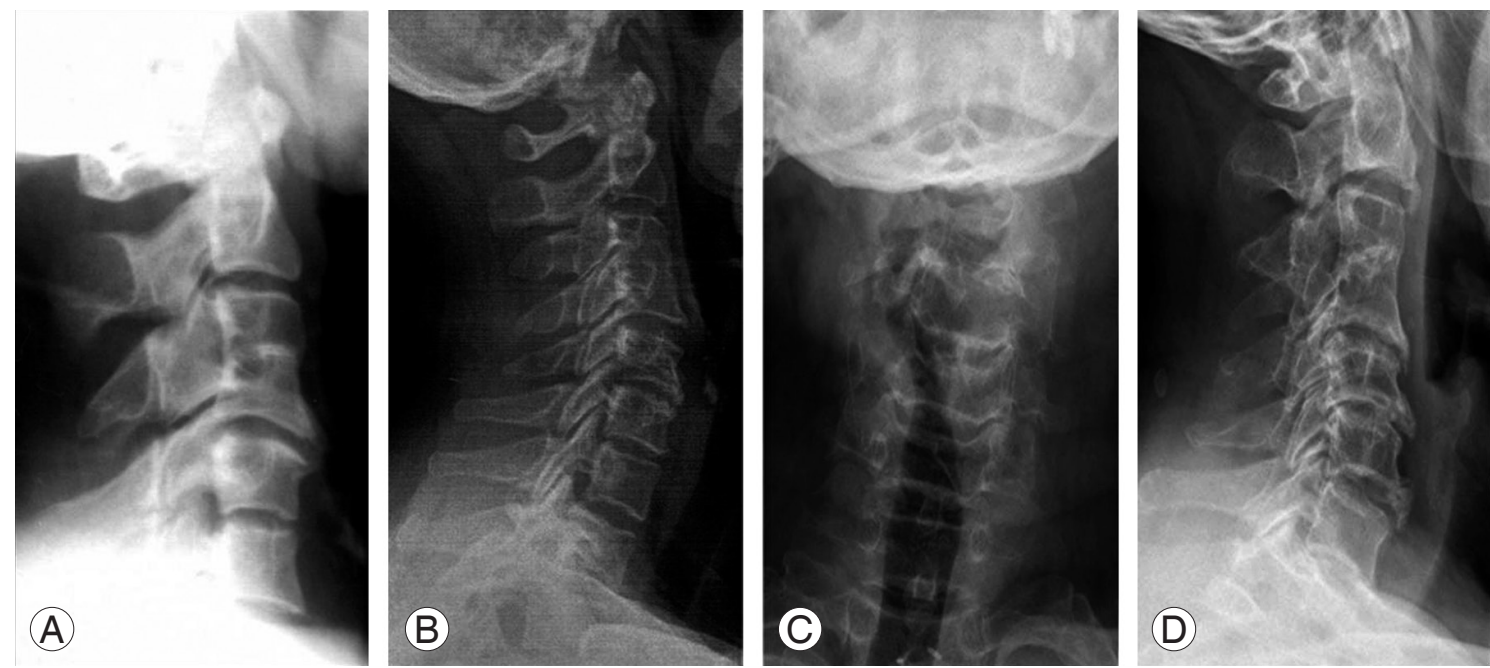

Fig. 6. Lateral radiograms of two patients, aged 40 years (A) and 42 years (B) with congenital C3-4 synostosis showing corporal flaring of the caudal half of the C3-4 block vertebra. In the (A) radiogram, the discs are not narrowed at the C4-5 and C5-6 levels, while on the (B) radiogram, mild disc degeneration is observed at C5-6 and C6-7, but not at C4-5. Radiograms of the cervical spine in a 69 year-old man (C, D), showing the flared caudal half of the synostotic C3-4 vertebrae; however, the upper part of C5 body did not develop the adaptive corporal flaring. Severe degeneration of the C4-5 and C5-6 discs, and large anterior claw spurs at the inferior margins of $\mathrm{C} 4, \mathrm{C} 5$, and $\mathrm{C} 6$ are shown. However, the C6-7 disc was not narrowed. 
and C6-7 (1) (Fig. 7).

4) Among 10 C5-6 synostosis patients, 7 (70\%) had spondylosis; $\mathrm{C} 3-4 / \mathrm{C} 4-5$ in 4 and $\mathrm{C} 6-7 / \mathrm{C} 7-\mathrm{T} 1$ in 8 patients (Fig. 8).

In summary, spondylosis was mostly confined to the adjacent segments, particularly the caudal segments. None of the cases were complicated by segmental hypermobility such as rotational and/or translational instability (Table 1).

Vertebral flaring of the caudal part of the C3-4 synostotic vertebra and the matching flaring of the upper part of the adjacent $\mathrm{C} 4$ vertebral body were most commonly seen together with relatively advanced ASD and remarkable inwaisting. However, these adaptive corporal morphological changes became less conspicuous in the cases of more caudal vertebral synostosis. Corporal inwaisting was the least in $\mathrm{C} 2-3$ synostotic vertebra and the most conspicuous in C3-4 synostotic vertebra, and became less the more caudal the synostotic vertebrae became, with less mobile segments.

\section{Discussion}

Intervertebral discs of the normal spine degenerate gradually in the course of the natural aging process. However, there are notable differences in the anatomy and loading characteristics between the cervical and lumbar spines which result in differences in the pattern of involvement, rate of degeneration and clinical presentation [16-21]. Unlike the lumbar spine, the cervical intervertebral discs experience significantly less axial loading over time. The cervical spine, anatomically, is also characterized by the presence of the uncovertebral joint. Luschka's joints contain fibrocartilage that can narrow and form osteophytes during the course of degeneration. Although the uncovertebral joints are less than one-third of the normal disc height, they are able to bear some of the axial load imparted to the cervical spine, thereby decreasing the overall loads placed on the intervertebral discs. These factors help to make the clinical entity of cervical disc herniation rare in individuals younger than 30 years and more common later during the fifth and sixth decades of life. Also
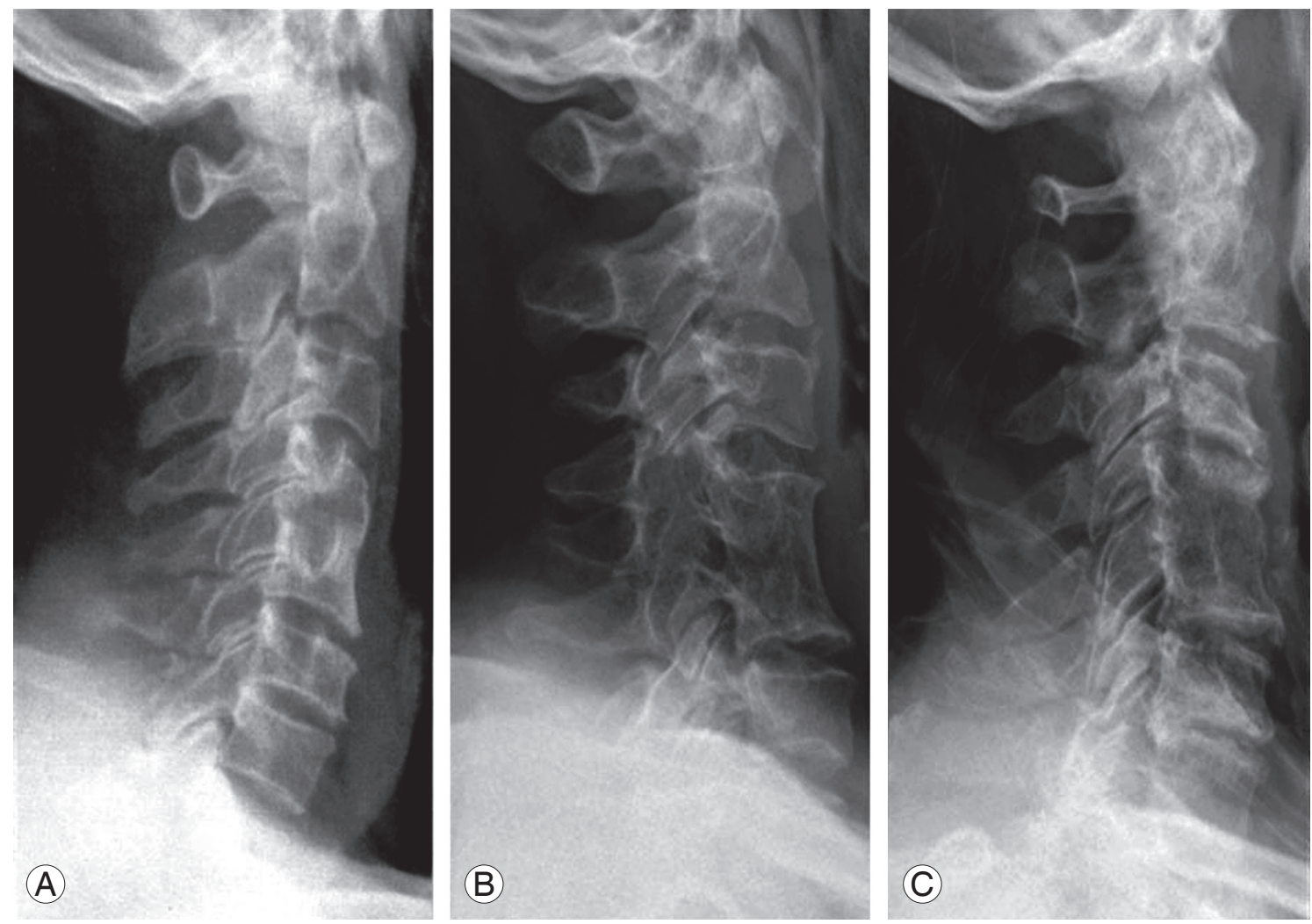

Fig. 7. Lateral radiograms of 3 patients with congenital C4-5 synostosis (A-C), aged from 56 to 90 years, showing a slightly inwaisted fused vertebral body with some caudal corporal flaring. In all 3 patients, spondylotic changes were observed at the proximal and caudal discs, respectively. 
the incidence of post-fusion adjacent segment pathology in the cervical spine is less than that of the lumbar spine.

Up until now, no one has studied adjacent segment pathology in the case of congenital monosegment synostosis in normal sagittal alignment, although the authors could find studies of the cervical spine in Kippel-Feil's syndrome. It is considered that congenital monosegment synostosis of the lower cervical spine may alter kinemat- ics and exert extra stress on the adjacent unfused/mobile segments, resulting in progressive joint degeneration and segmental instability, which are seen frequently in cases of surgical fusion [15].

Disc degeneration at the adjacent joints after surgical cervical spine fusion has now become a really menacing problem because its reported incidence is high: $2.5 \%$ per annum and it has become $25 \%$ in 10 years. The contro-

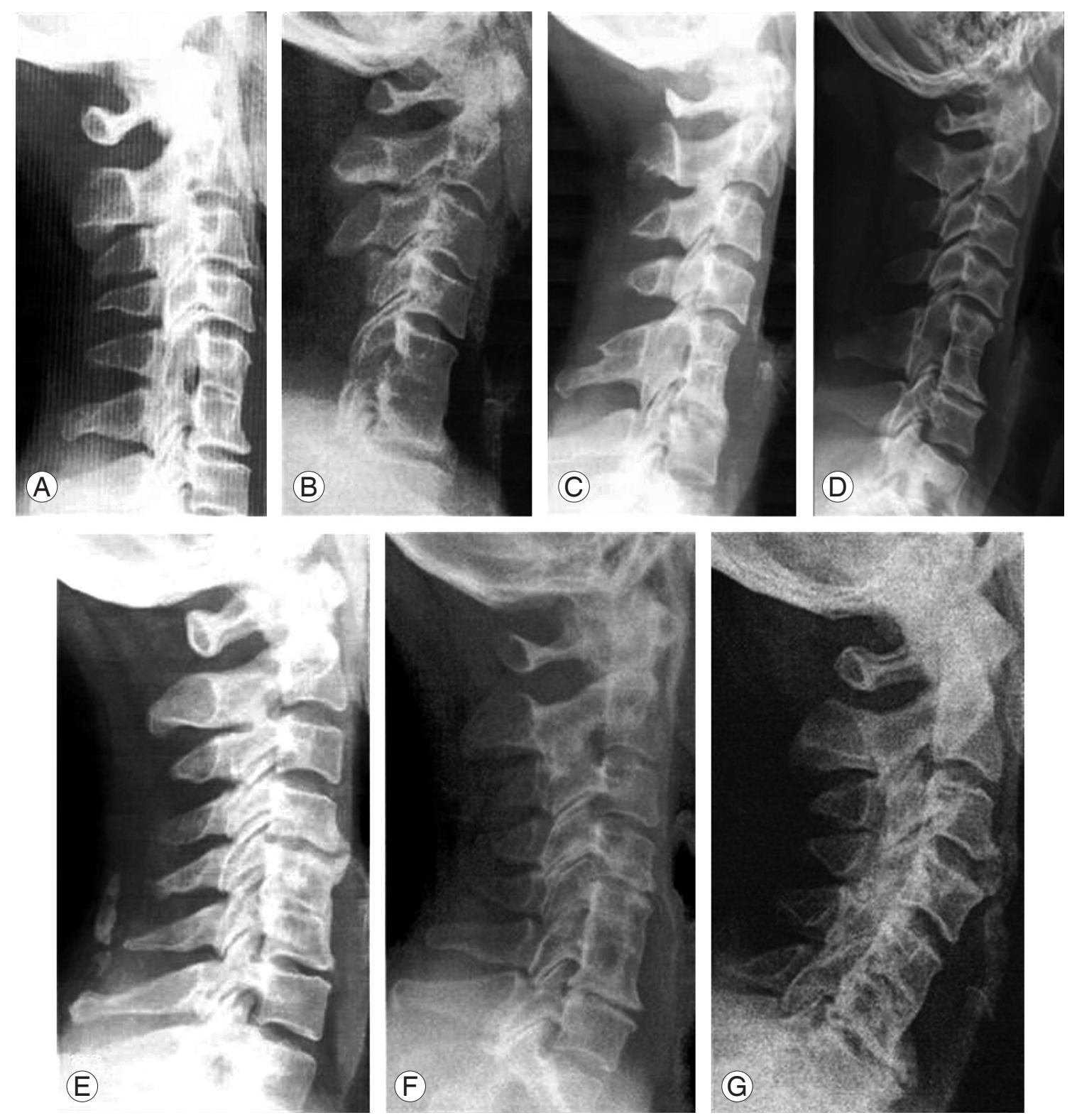

Fig. 8. Lateral radiograms of 7 subjects with C5-6 synostosis in normal alignment, aged 43 years (A), 44 years (B), 46 years (C), 51 years (D), 41 years (E), 58 years (F), and 67 years (G), showing the various degrees of disc degeneration with the flattened curve. In none of these patients were the cranial discs degenerated. Vertebral inwaisting is less evident. (E) Advanced disc degeneration at the adjacent cranial C4-5 segment and early disc degeneration at the caudal C6-7 segment. Loss of the normal lordotic curve is seen. (F) Relatively advanced disc degeneration is seen at both the immediate adjacent cranial (C4-5) and caudal (C6-7) discs. (G) Relatively advanced disc change is seen only at the caudal (C6-7) segment, but the cranial discs are all well preserved. 
versial issue related with $\mathrm{ASD}$ is whether the ASD is a natural constitutional phenomenon or an iatrogenic one. To solve this controversial issue as the first step of an investigational study, congenital synostosis models were chosen as the control [15-18].

ASD has been known to be associated with age, presumably due to differences in physical adaptability to stress between children and adults. However, there has been argument over whether the fused spine transfers its lost bearing load and motion to the adjacent segments which are forced to compensate for the lost bearing load and motion. Also, there are conflicting reports on whether this actually occurs, and whether there is an observable relationship between motion and development of disc degeneration after the fusion.

In our study, ASD was mostly localized to the adjacent joints, particularly the caudal ones in the cases of synostosis between $\mathrm{C} 2-\mathrm{C} 6$. The interesting findings were that in the cases of $\mathrm{C} 2-3$ synostosis, ASD developed in the immediate cephalad unilateral facet joint $(\mathrm{C} 1-\mathrm{C} 2)$, and that mostly caudal segments below $\mathrm{C} 4-5$ were involved by skipping the C3-4 segments. This fact suggested indirectly that the normally aligned C2-3 synostosis did not affect the immediate caudal segment (C3-4). Even the kyphotic $\mathrm{C} 2-3$ block vertebra did not precipitate ASD earlier than the normally aligned one, although the compensatory hyperlordosis below $\mathrm{C} 2-3$ block resulted in spondylosis at the C3-4 segment and C4 retrolisthesis at the apex of the hyperlordosis, which was not shown in the normally aligned segment of any level. Thus, it is speculated that the pediatric spine adapts well even to altered biomechanics. ASD in monosegment synostosis could be related to the block vertebra, because the discs distant from the fused vertebra were kept intact or were minimally degenerated in the current series.

In summary the adjacent disc degeneration seemed primarily to be precipitated by the constitutional factors including age, and additionally was exacerbated by the direct load and motion shift in a certain degree from the fused segments because disc degeneration was not observed before the age of 35 years regardless of the fusion alignment.

Also a question could be raised as to whether disc degenerates faster and more severely by fusion or not, and when the more compensatory role of the adjacent mobile segment starts to become imposed. Also it is assumed that ASD is unrelated with hypermobility secondary to synsostosis. Normal cervical lordosis could not be maintained in patients with multisegment spondylosis.

Through this study, it was again confirmed that the pediatric spine could adapt well to biomechanical alterations. Consequently, the adjacent motion segments of the monosegment block vertebra could compensate for the loss in motion and load by developing 1) the strong soft tissue stabilizers without losing the original supporting and mobility functions, and 2) adaptive morphological changes such as broadening of the disc, matching with the flared vertebral body and vertebral body inwaisting [20]. However, it is evident that the adult spine adapts poorly to the altered biomechanics, and that it can not develop the adaptive morphological changes seen in the pediatric spine except for corporal inwaisting.

Corporal flaring of the synostotic vertebra and disc enlargement are the most characteristic features of C3-4 synostosis, and are the manifestations of the morphological adaptations together with the corporal inwaisting that develop to meet the biomechanical need in the pediatric spine. The corporal flaring became less evident in the C4-5 synostotic vertebra and was not seen in the C5-6 synostotic vertebra.

Vertebral body inwaisting in general is seen in the normal human spine, in people aged over 2 years [17]. In the motionless spine such as in ankylosing spondylitis, each vertebral body is squared without inwaisting $[17,18]$. When segmental motion is excessive, more inwaisting develops [20]. This phenomenon suggests indirectly the degree of motion range at each motion segment. In the current series, inwaisting became less evident in the C5-6 synostotic vertebra and in the elderly with less mobile segments above and below due to spondylosis.

Limitations of this study were the small number of cases, the absence of cases with variably severe kyphotic fusion and the absence of cases that were not age-related among the cases of surgically fused monosegment synostosis that acted as controls.

It is debatable whether congenitally and surgically fused vertebrae affect the adjacent mobile segments in a similar way [1,15-21]. This would be possible only if 1 ) the segments adjacent to the block vertebrae are truly normal to start with, and 2) the side effects of the surgical fusion are negligible. Both assumptions are speculative [3]. Our findings on congenital monosegment synostosis of the lower cervical spine between C2-C6 may not be comparable to those of the surgically fused ones. There- 
fore, it is speculated that even normally aligned congenital monosegment synostosis is likely to precipitate the development of adjacent joint disease, though late in life. Thus, it could be concluded that synostosis is an ASDprecipitating factor which is not benign clinically, though none of the cases in the current series were subjected to surgical care because of ASD.

\section{Conclusions}

Spondylosis at the mobile segment in a synostotic cervical spine is thought to be a fusion-related pathology rather than solely age-related disc degeneration. The resultant data suggested that congenital monosegment synostosis precipitated definitely the ASD.

\section{Conflict of Interest}

No potential conflict of interest relevant to this article was reported.

\section{References}

1. Frobin W, Leivseth G, Biggemann M, Brinckmann P. Sagittal plane segmental motion of the cervical spine. A new precision measurement protocol and normal motion data of healthy adults. Clin Biomech (Bristol, Avon) 2002;17:21-31.

2. Epstein NE, Epstein JA, Zilkha A. Traumatic myelopathy in a seventeen-year-old child with cervical spinal stenosis (without fracture or dislocation) and a C2-C3 Klippel-Feil fusion. A case report. Spine (Phila Pa 1976) 1984;9:344-7.

3. Leivseth G, Frobin W, Brinckmann P. Congenital cervical block vertebrae are associated with caudally adjacent discs. Clin Biomech (Bristol, Avon) 2005;20:669-74.

4. Hall JE, Simmons ED, Danylchuk K, Barnes PD. Instability of the cervical spine and neurological involvement in Klippel-Feil syndrome. A case report. J Bone Joint Surg Am 1990;72:460-2.

5. Ross J, Myles L. Cervical spine problems in children. Current Orthopaedics 2006;20:274-85.

6. Tracy MR, Dormans JP, Kusumi K. Klippel-Feil syndrome: clinical features and current understanding of etiology. Clin Orthop Relat Res 2004;(424):183-90.

7. Hensinger RN. Congenital anomalies of the cervical spine. Clin Orthop Relat Res 1991;(264):16-38.

8. Eck JC, Humphreys SC, Lim TH, et al. Biomechanical study on the effect of cervical spine fusion on adjacent-level intradiscal pressure and segmental motion. Spine (Phila Pa 1976) 2002;27:2431-4.

9. Ducker TB. Cervical myeloradiculopathy: KlippelFeil deformity. J Spinal Disord 1990;3:439-40.

10. Lee $\mathrm{CK}$, Weiss $\mathrm{AB}$. Isolated congenital cervical block vertebrae below the axis with neurological symptoms. Spine (Phila Pa 1976) 1981;6:118-24.

11. Nagib MG, Maxwell RE, Chou SN. Identification and management of high-risk patients with Klippel-Feil syndrome. J Neurosurg 1984;61:523-30.

12. Baba H, Maezawa Y, Furusawa N, Chen Q, Imura S, Tomita K. The cervical spine in the Klippel-Feil syndrome. A report of 57 cases. Int Orthop 1995;19:2048.

13. Ritterbusch JF, McGinty LD, Spar J, Orrison WW. Magnetic resonance imaging for stenosis and subluxation in Klippel-Feil syndrome. Spine (Phila Pa 1976) 1991;16:S539-41.

14. Samartzis DD, Herman J, Lubicky JP, Shen FH. Classification of congenitally fused cervical patterns in Klippel-Feil patients: epidemiology and role in the development of cervical spine-related symptoms. Spine (Phila Pa 1976) 2006;31:E798-804.

15. Moon MS, Kim SS, Lee BJ, Moon JL, Lin JF, Moon YW. Radiographic assessment of congenital C2-3 synostosis. J Orthop Surg (Hong Kong) 2010;18:1437.

16. Panjabi M, Malcolmson G, Teng E, Tominaga Y, Henderson G, Serhan H. Hybrid testing of lumbar CHARITE discs versus fusions. Spine (Phila Pa 1976) 2007;32:959-66.

17. Moon MS, Kim JM. The effect of mechanical forces on vertebral growth-A preliminary report. J Western Pacif Orthop Assoc 1974;XI-2:1-26.

18. Moon MS, Moon JL, Ha KY, Kim KW. Re: Does spinal kyphoitc deformity influence the biomechanical characteristics of the adjacent motion segment? An in vivo animal model. Spine (Phila Pa 1976) 2000;25:1739-41.

19. Chen WJ, Lai PL, Tai CL, Chen LH, Niu CC. The effect of sagittal alignment on adjacent joint mobility after lumbar instrumentation--a biomechanical study of lumbar vertebrae in a porcine model. Clin Biomech (Bristol, Avon) 2004;19:763-8. 
20. Moon MS, Moon YW, Kim SS, Moon JL. Morphological adaptation of the bone graft and fused bodies after non-instrumented anterior interbody fusion of the lower cervical spine. J Orthop Surg (Hong Kong) 2006;14:303-9.
21. Yang JY, Lee JK, Song HS. The impact of adjacent segment degeneration on the clinical outcome after lumbar spinal fusion. Spine (Phila Pa 1976) 2008;33:503-7. 